\title{
Teknik Olmayan Enerji Kayıplarının Azaltılmasında PLC Sayaçlarının Önemi
}

\author{
Behçet KOCAMAN* \\ Bitlis Eren Üniversitesi, Elektrik Elektronik Mühendisliği Bölümü, Bitlis
}

\begin{abstract}
$\ddot{O} \mathbf{z}$
Günlük yaşantımızı normal bir şekilde devam edebilmemiz için kullandığımız elektrik enerjisi, su ve doğal gaz gibi vazgeçilmez bir kaynaktır. Elektrik enerjisinin üretimi hem zor hem de pahalıdır. Üretimde kullanılan kaynakların sınırlı olması ve enerjiye olan talebin her geçen gün artması nedeniyle mevcut kaynakların yerinde kullanılması gerekir. Elektrik enerjisinin yerinde ve doğru kullanılmamasıyla üretiminden tüketimine kadar olan safhalarda teknik ve teknik olmayan kayıplar oluşmaktadır. Yapılan çalışmalarda ülkemizdeki enerji kayıp kaçak oranının \% 14 civarında olduğu tespit edilmiştir. Bu değer, gelişmiş ülkelerdeki kayıp kaçak oranlarından çok fazladır. Avrupa ülkelerinde ise bu oran, \% 6 seviyesindedir. Bu yüzden kullanılan elektrik enerjisi miktarının, su ve doğal gaz gibi izlenmesi, ölçülmesi ve faturalandırılması gerekir. Bu işlem için kullanılan en önemli yöntemlerden biri izlenme yöntemidir. Günümüzde eskisi gibi sayaç yanına gidip okuma yapmak yerine farklı haberleşme yöntemleri ile Otomatik Sayaç Okuma Sistemi (OSOS) sistemlerine dahil olunmakta ve birçok faydası ile kullanılmaktadır. PLC (Güç hattı üzerinden haberleşme) haberleşme, son zamanlarda kablolu ve kablosuz olarak kullanılan birçok haberleşme yönteminden en çok tercih edilenlerden biridir. Bu çalışmada; PLC teknolojisi ile akıllı sayaç (PLC sayaç) hakkında bilgiler verilmiş ve PLC sayaçların kullanılmasının teknik olmayan enerji kayıplarının azaltılmasındaki önemi örnek bir alan üzerindeki veriler dikkate alınarak belirtilmiştir. Ayrıca PLC sayaçların kullanılması ile ilgili önerilerde bulunulmuştur.
\end{abstract}

Anahtar kelimeler: Akıllı Sayaç, Kayıp Kaçak, PLC.

\section{The Importance of PLC Meters in Reducing Non-Technical Energy Losses}

\begin{abstract}
Electric energy that we use to keep our daily life in a normal way is an indispensable source like water and natural gas. Electric energy generation is both difficult and expensive. Since the resources used in generation are limited and the demand for energy increases day by day, existing resources need to be used in place. Because of inaccurate and inefficient use of electrical energy consist of technical and non-technical losses from generation to consumption. In studies done it has been found out that the rate of energy loss leakage in our country is around $14 \%$. This value is much higher than the loss leakage rates in developed countries. In European countries, this rate is $6 \%$. Therefore, the amount of electric energy used must be monitored, measured and billed like water and natural gas. One of the most important methods used for this process is the monitoring method. Nowadays, instead of reading to the meter like the old, with various communication methods be included Automatic Meter Reading System (AMRS) to systems and they are used with many benefits. PLC (Power Line Communication) communication is one of the most preferred among the many communication methods that have been used recently in wired and wireless. In this study; the information has been given about smart meter (PLC meter) with PLC technology and the importance of using PLC meters to reduce non-technical energy losses has been stated considering the data on a sample area. In addition, suggestions have been made regarding the use of PLC meters.
\end{abstract}

Keywords: Smart Meter, Loss Leakage, PLC.

*Sorumlu yazar: bkocaman@beu.edu.tr

Geliş Tarihi: 01.05.2018, Kabul Tarihi: 10.10.2018 


\section{Giriş}

Elektrik enerjisi, günlük yaşantımızın vazgeçilmez bir unsurudur. Bu enerjinin yanlış ve etkin olmayan bir şekilde kullanılması sonucunda enerjinin üretildiği santrallerden tüketim noktasına gelinceye kadar olan safhalarda teknik ve teknik olmayan kayıplar oluşmaktadır. Bu kayıpları azaltmak, mevcut enerji sistemlerinden daha verimli faydalanmayı sağlar [1]. Böylece enerjideki arz ve talep dengede tutulabilir. Elektrik enerji sistemlerinde oluşan enerji kayıpları, teknik ve teknik olmayan kayıplar olarak iki kısma ayrilır. Teknik kayıplar, elektrik enerji sistemlerinde kullanılan teknik malzeme ve donanımlarda oluşan kayıplardır. Bunlar, enerji üretiminin yapıldığı santrallerden başlayarak iletim ve dağıtım hatları boyunca tüketiciye ulaşıncaya kadar sürmektedir [2]. Teknik olmayan kayıplar ise; doğrudan tüketicinin enerjiyi kullanma şeklinden dolayı oluşan kayıplardır. Bu kayıpların başlıca nedenleri; sayaçlara yapılan müdahaleler ile kaçak enerji kullanımı, bilinçsiz enerji tüketimi ve dağıtım şirketlerinde enerjiyi faturalandırma sırasında yapılan hatalar gösterilebilir [3]. Yapılan araştırmalarda ülkemizdeki kayıp kaçak oranının gelişmiş ülkelerdeki kayıp kaçak oranlarından fazla olduğu tespit edilmiştir. Örneğin Van, Bitlis, Muş ve Hakkari ilerinin bağlı olduğu Vangölü Elektrik Dağıtım A.Ş. (VEDAŞ) yetkililerinin yaptığ açıklamaya göre 2017 yılı sonu itibarıyla kayıp kaçak oranlarının Hakkari ilinde $\% 72$, Van ilinde $\% 53$, Muş ilinde $\% 48,5$ ve Bitlis ilinde $\% 35$ civarında olduğu belirtilmiştir. $\mathrm{Bu}$ nedenle özellikle teknik olmayan kayıpları azaltmak için tüketilen enerjinin doğru bir şekilde ölçülmesi, izlenmesi ve faturalandırılması önemlidir. Bunun için haberleşme alt yapısına ihtiyaç duyulmaktadır.

Haberleşme altyapısı, akıllı sayaç uygulamalarının temel bileşenleri olan sayaç ve veri merkezi arasındaki iletişimin sağlandığı donanım ve yazılım ortamıdır. Sayaç, temel olarak, tüketim noktasında tüketilen enerjiyi ölçmeyi sağlayan ölçü cihazıdır. Bu cihaz, teknolojisine göre mekanik ve elektronik olarak sınıflandırılır, takılı olduğu tüketim noktasındaki bağlantı şekline göre de tek fazlı veya üç fazlı türleri olabilmektedir. Bununla birlikte büyük güç çeken tüketim noktalarında kullanılan sayaçlar, akım ve gerilim trafolarıyla beraber kullanılmaktadır. Akıllı sayaçlar ise, yaptığı ölçümleri hafızasında tutabilen ve farklı haberleşme portlarıyla dış sistemlerle paylaşabilen sayaçlardır. Enerji şirketleri, elektrik şebekelerini ve ölçüm sistemlerini yükseltmek ve sayısallaştırmak için milyarlarca dolar harcamaktadır. Yapılan harcamalar ile akıllı şebekelerin alt yapısı oluşturulmaktadır. Akıllı şebeke, bilgi toplamak ve hareket etmek için bilgi ve iletişim teknolojisini kullanan modern bir elektrik şebekesi sistemidir. Yapılan alt yapı sayesinde akıllı şebekeye uygun kullanılan akıllı sayaçlar için, operasyonları ve ortamları hakkında çok sayıda gerçek zamanlı veriyi raporlamada gömülü, akıllı sensörler kullanılmaktadır. Birçok ülkede akıllı sayaç periyodik verilerinin toplanması için PLC kullanılmaktadır. PLC'nin maksimum test edilen bant genişliği $41 \mathrm{MB} / \mathrm{s}^{\prime}$ dir [4]. Bu çalışmada, PLC modüllü sayaçların kullanılmasının teknik olmayan enerji kayıplarının azaltılmasındaki önemi örnek bir alan üzerindeki veriler dikkate alınarak belirtilmiştir.

\subsection{PLC Teknolojileri}

PLC teknolojileri; ultra dar, dar ve geniş bant olmak üzere üç alana ayrılmaktadır [5]. Ultra dar bant; düşük frekanslarda çok az veri akış1 (100 bps) işlemektedir. Bu özellikle yük kontrolü için kullanılan tek yönlü iletişimi kullanır. Aynı zamanda çok geniş bir operasyon aralığına sahiptir (yüzlerce kilometre). Dar bant; Avrupa'da 3 - 148,5 kHz bandında faaliyet göstermektedir. Tek taşıyıcı dar bant teknolojileri birkaç kbps'lik veri hızlarına ulaşır. Günümüzde, 500 kbps'ye varan veri hızlarına sahip çok kanallı teknolojiler sıklıkla kullanılmaktadır. Geniş bant; 1,8 - $250 \mathrm{MHz}$ yüksek frekans bantlarında çalışır ve yüzlerce Mbps'ye kadar saniyede birkaç MB veri hızına sahiptir. PLC, geniş bant iletişimi için en uygun erişim teknolojilerinden biridir.

Dünyada birçok teknolojik yenilikler alınmasına rağmen mevcut elektrik enerjisi tüketiminin faturalandırılması süreci var olan son teknoloji ile karşılanmamaktadır. Bu nedenle PLC gibi teknolojilerden faydalanılmaktadır. PLC teknolojilerinin birçok avantajı bulunmaktadır. Örneğin güç kalitesi uygulamalarında kullanılan PLC, modemin iletişim ve sensör olarak kalite ölçümü için tasarlanabilmesi gibi iki amacı vardır [6]. Aynı avantaj, tek sistemde iki uygulamanın birleşimi olan elektrik izleme ve ileri enerji yönetimi teknikleri için faydalı olabilir. PLC kullanmanın bir diğer avantajı, ihtiyaç fazlası gerektiren uygulamalar için bir yedek iletişim kanalıdır [7]. PLC ayrıca, yardımcı programın kontrolü altındaki bir iletişim kanalı sağlar [8]. Belki de endüstri için en uygun 
çözüm PLC'dir. Bu teknoloji, bilgi aktarımı için özel kabloların yerleştirilmesindeki ana problemi çözen güç hattı kanalını benimsemektedir [9].

Geleneksel olarak PLC, çeşitli akıllı şebeke uygulama alanları olan güç şebekesinin otomasyonunda, kablosuz bağlantıya alternatif olarak akıllı sayaç bağlantılarında ve akıllı cihazların bağlantılarıyla ev otomasyonunda yaygın olarak kullanılmaktadır [10-13].

PLC'nin şu ana kadar ki temel dezavantajı standardizasyon eksikliğidir. Fiber bağlantı teknolojileri sağlam, güvenilir ve yüksek hızlı iletişim sağlamalarına rağmen oldukça pahalıdır. PLC'nin bağlantı teknolojileri ile karşılaştırmaları Tablo 1'de verilmiştir. Tablo 1'de görüldüğü gibi PLC, sabit hat veya kablosuz bağlantı teknolojilerine kıyasla önemli avantajlar sunmaktadır [14].

Tablo 1. PLC ile kablosuz bağlantı teknolojilerinin karşılaştırılması

\begin{tabular}{lcccccc}
\hline \multicolumn{1}{c}{$\begin{array}{c}\text { Bağlantı } \\
\text { Teknolojisi }\end{array}$} & Maliyet & Yayılma & Veri Oranı & Topoloji & Terminal & $\begin{array}{c}\text { İletişim } \\
\text { Alanı }\end{array}$ \\
\hline Uydu & Pahalı & Basit & $155 \mathrm{Mbps}$ & Çoklu nokta & Sabit & $1000-36000 \mathrm{~km}$ \\
Mikro dalga & Pahalı & Zor & $155 \mathrm{Mbps}$ & Çoklu nokta & Sabit & $5 \mathrm{~km}$ \\
LMDS & Pahalı & Zor & $155 \mathrm{Mbps}$ & Çoklu nokta & Ayarlı & $4 \mathrm{~km}$ \\
MMDS & Pahalı & Zor & $10 \mathrm{Mbps}$ & Çoklu nokta & Sabit & $100 \mathrm{~km}$ \\
FSO & Pahalı & Zor & $2.5 \mathrm{Gbps}$ & Çoklu nokta & Sabit & $4 \mathrm{~km}$ \\
WiFi & Ucuz & Basit & $11 / 54 \mathrm{Mbps}$ & Çoklu nokta & Hareketli & $100 \mathrm{~km}$ \\
3G ve 4G & Pahalı & Kolay & $1-10 \mathrm{Mbps}$ & Çoklu nokta & Hareketli & Hareket alanı \\
& & & & & ile sinırlı \\
PLC & Ucuz & Kolay & $200 \mathrm{Mbps}$ & Çoklu nokta & Sabit & $\begin{array}{c}\text { Gerilime } \\
\text { göre çeşitli }\end{array}$ \\
\hline
\end{tabular}

Veri alış verişinde kablolu ve kablosuz olarak birçok haberleşme yöntemi kullanılmaktadır. Kablolu iletişim için koaksiyel kablolar ve fiber-optik kablolar kullanırlar. Kablosuz iletişimde ise, veriler hava ya da uzayda kızılötesi, radyo ve mikrodalga sinyalleri ile iletilir. Kablosuz mobil ağları tanımlayan kısaltmalar aşağıda belirtilmiştir.

GPRS (General Packet Radio Service), mevcut cep telefonu şebekesi üzerinden paket anahtarlamalı olarak veri iletimi sağlayan teknolojidir.

RF (Radio Frequency) yüksek frekanslı dalgadır. Bu frekans, $3 \mathrm{kHz}-300 \mathrm{GHz}$ arasındadır. Mikrodalga frekans bandı, RF bandı içinde yer alıp birkaç yüz MHz'ten birkaç GHz'e kadar olan frekans bandını kapsar.

CDMA (Code Division Multiple Access) ileri teknoloji bir mobil iletişim teknolojisidir. CDMA taşıyıcıları, ağında kullanımına izin verdiği tüm telefonların bir listesini tutar. Telefonlar ESN (elektronik seri numara) koduna göre izlenir, bu sayede cep telefonu iletişim protokolü olan GSM (Global System for Mobile) operatörlerinin sunmuş olduğu servislerden faydalanmaya yardımcı olan bir mikroçip olan SIM (Subscriber Identity Module) kartına ihtiyaç duyulmaz. CDMA telefonlar etkinleştirildikten sonra ilgili ağa direkt olarak bağlanabilir.

3G: (D:384 Kbit/s-U:384 Kbit/s). UMTS(Universal Mobile Telecommunication Service)'nin simgesidir. UMTS ağını kullananlar, 3. Jenerasyon olarak kabul edilir.

PSTN (Public Switched Telephone Network) dünya genelinde kullanılan devre aktarmalı telefon ağıdır. Başlangıçta sabit analog telefon şebekesi olarak kurulan bu ağ, günümüzde neredeyse tamamen sayısaldır ve sabit telefonların yanı sıra mobil telefon hatlarını da içermektedir.

Haberleşme yöntemlerinden hangisinin kullanılacağına kurulumu yapılacak bölgenin özellikleri, mevcut veya gelecekte yapılması planlanan sistemlerle sağlanacak sinerji gibi faydalar göz önüne alınarak yapılan saha çalışmasına göre belirlenmektedir. Örnek olarak; yoğun elektrik şebekesinin bulunduğu yerlerde GPRS veya RF çözüm olarak kullanılmaktadır. Ancak, RF haberleşmenin kullanılamadığı bazı kırsal yerlerde ise PLC teknolojisi kullanılmaktadır. Bununla birlikte son zamanlarda kablolu ve kablosuz olarak kullanılan haberleşme yöntemlerinden en çok tercih edilenlerden biri PLC haberleşmedir. Bu haberleşme, kablolu veya kablosuz ilave bir alt yap1 gerektirmeyen bir yapıya sahiptir. Mevcut kullanılan enerji dağıtım hatları, haberleşme altyapısı olarak kullanılmaktadır. Bu nedenle sistemin kurulacağı yer için ek haberleşme altyapısına ihtiyaç olmaz ve tek başına çekilen besleme hatları yeterli olmaktadır. Bu besleme hatları haberleşmede daha avantajlıdır. Çünkü günümüzde daha uzun mesafelerde, gürültülü ortamlarda, daha yüksek hız gerektiren yerlerde, daha çok alıcı vericinin gerektiği yerlerde kullanılmak üzere geliştirilmiş bir seri iletim ortamı olan 
RS485 ve Ethernet için ek haberleşme kabloları olarak 0,75 veya $1 \mathrm{~mm}^{2}$ kesitinde iletkenler kullanılmaktadır. Bu iletkenlerde kopma problemleri çok fazla olmaktadır. Bu kopma problemleri, enerji dağıtım hatlarının haberleşme kabloları olarak kullanılmasıyla ortadan kalkmakta ve cihaz sunucusu gibi donanım arızaları da oluşmamaktadır.

Besleme hatlarının bir diğer avantajı da kablolama veya GSM operatör maliyetleri ödenmediği ve birçok dönüştürücü ara donanım maliyeti gerektirmediği için ekonomik sağlamasıdır. Ayrıca bu sistem, her yerde çalışabilecek şekilde tasarlanabilmektedir. Bu haberleşme sistemi kurulduktan ve sistem içinde kullanılan elektrik sayaçları takıldıktan sonra merkezi toplayıcı ünitesi tarafindan tanımlanmaktadır. Dolayısıyla haberleşme ayarları ve protokol entegrasyonları gibi ek çalışmalara gerek kalmamaktadır. Sistemde bulunan merkezi veri toplama birimi de kayıt yapmakta ve bu birimler sayesinde elektrik sayaçlarının eş zamanlı çalışmaları kolaylıkla yapılabilmektedir. Benzer bir sistemin şematik gösterimi Şekil 1'de verilmiştir.

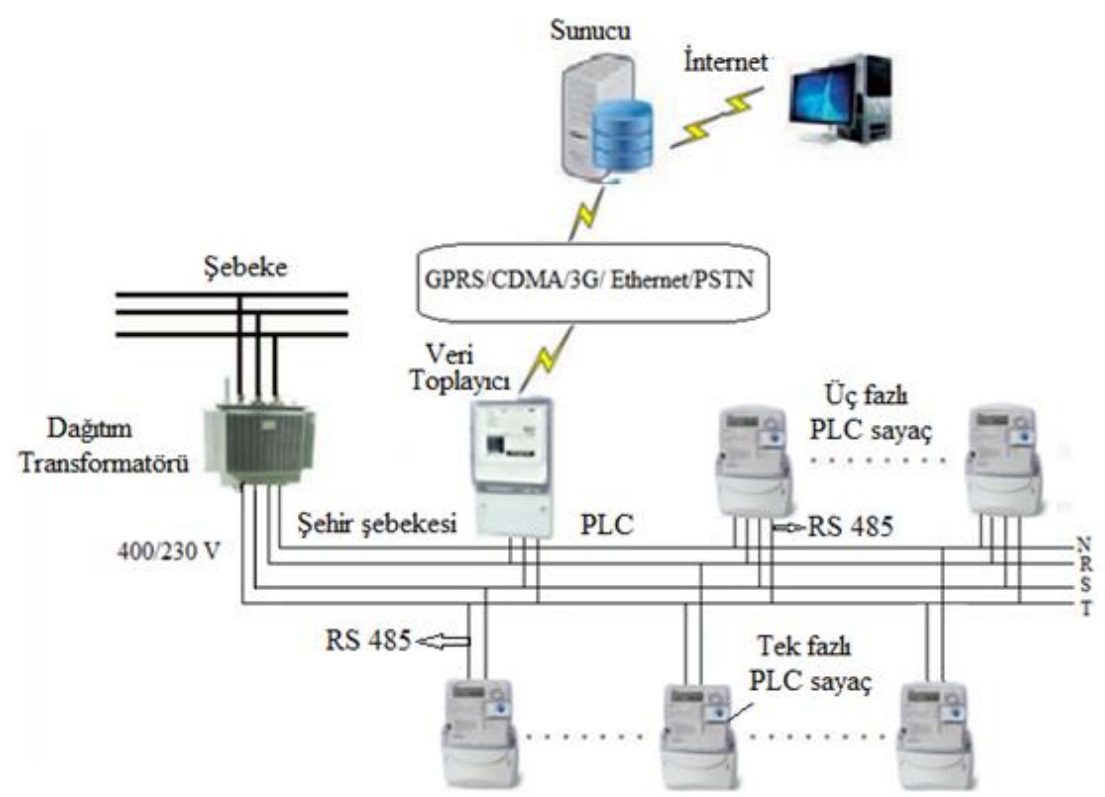

Şekil 1. PLC haberleşme sistemi şematik gösterimi

Haberleşme amacıyla, frekansı $50 \mathrm{~Hz}$ olan enerji dağıtım hatları üzerine frekansı $\mathrm{kHz}$ mertebesinde olan ek sinyaller konulmaktadır. Bu sinyaller, filtreleme teknolojisi yardımıyla merkezi toplayıcı cihazlarda buluşup özel ağlara entegre edilmektedir.

Uzaktan okunabilen sayaçlar; sayacın kendisi ve haberleşme ünitesi olmak üzere iki temel kısımdan oluşmaktadır. Bu sayaçlarla birlikte haberleşme üniteleri, donanım, yazılım ve mekanik olarak tümüyle modüler yapıda tasarlanmaktadır. Böylece GPRS modülü monte edilen sayaçlar GPRS teknolojisiyle haberleşebilir duruma gelir. Benzer şekilde PLC modülü takılan sayaçlar PLC teknolojisi üzerinden haberleşebilir duruma gelir. Dağıtım şirketleri, satmış oldukları enerjileri daha hatasız okumak, borç takip süreçlerini kolaylaştırmak, tahsilatlarını artırmak ve uzaktan sayaç okuma için akı1lı sayaç olarak da adlandırılan PLC sayaçlardan faydalanmaktadırlar. Bu işlem yapılırken veri iletim sistemine ve sayaca yapılabilecek muhtemel dış müdahaleler tespit edilebilmesi ve önlenebilmesi için veri iletiminin güvenliği sağlanmalıdır.

\section{Materyal ve Metot}

Elektrik enerjisinin daha etkin kullanılması için oluşan teknik olmayan kayıpların azaltılması gerekir. Bu kayıpların azaltılmasında enerji hattı üzerinden uzaktan okunabilen PLC sayaçların önemi büyüktür. Örnek uygulamada, VEDAŞ'ın PLC sayaç kullandığı bölgeler için elde ettiği verileri kullanılacaktır. VEDAŞ'ın sorumluluk alanı içerisinde bulunan Van, Hakkari, Muş ve Bitlis ilerinden seçilen Özalp (Van), Saray (Van), Bulanık (Muş) ve Güroymak (Bitlis) ilçelerinde PLC sayaç takılmadan önceki ve 
takıldıktan sonraki kaçak kayıpları karşıllaştııılmıştır. PLC sayaç takılan yerlerde tüketicilerin toplu veya müstakil bulunma durumuna göre farklı uygulamalar yapılmıştır.

Toplulaştırılmış alanlarda yani apartmanlardaki elektrik panolarında kullanılan tek fazlı veya üç fazlı PLC sayaçların her birinde PLC modüllü yoktur. Bu tür sayaçlar, RS485 portu ile PLC modeme seri bağlanarak haberleşmektedir. Böylece her sayaç için ayrı bir modem kullanılmadan, sadece bir modem ile bağlı olan tüm sayaçlar okunabilir. Böyle bir sistemin şematik gösterimi Ş̧ekil 2'de verilmiştir.

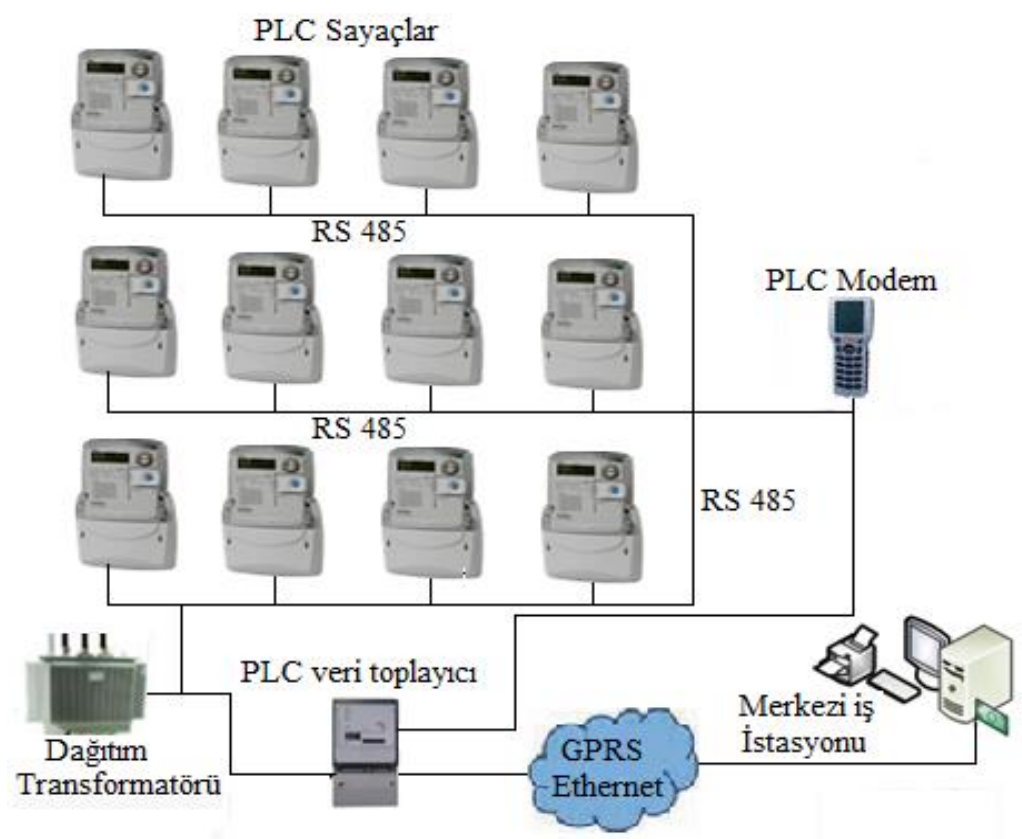

Şekil 2. Toplulaştırılmış alanlar için kullanılan PLC sayaç şematik gösterilimi

Tek başına bulunan yani müstakil evler için kullanılan PLC sayaçların içinde kendi PLC modüllü bulunmakta ve bu modül sayesinde transformatör merkezine kadar enerji hatları üzerinden haberleşme sağlanarak veri toplayıcısına iletilir. Alınan veriler GPRS teknolojisi yardımıyla sunucuya iletilmektedir [15]. Güçlü bir sunucu ve internet altyapısı sayesinde binlerce sayaç, çok kısa süre (saniyeler) içinde okunabilir. Böyle bir sistemin şematik gösterimi Şekil 3 ’te verilmiştir.

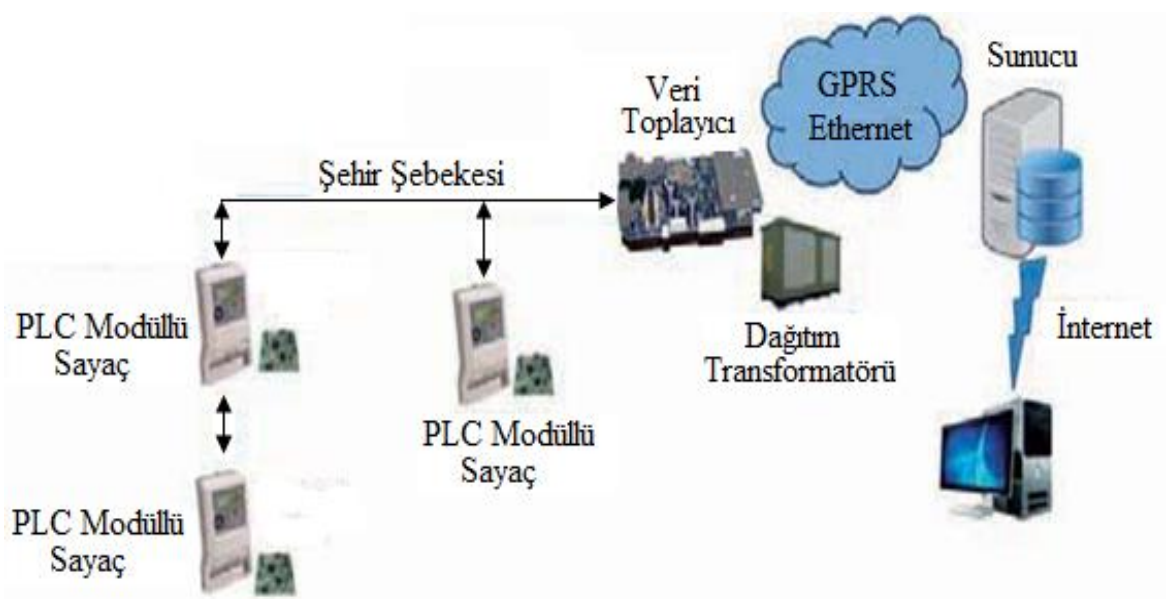

Şekil 3. Müstakil yerler için PLC sayaç bağlantıları şematik gösterimi [15]

Şekil 3’te verilen sistem için kullanılan kablosuz PLC modüllü ve PLC sayaç görüntüsü Şekil 4'te verilmiştir. 

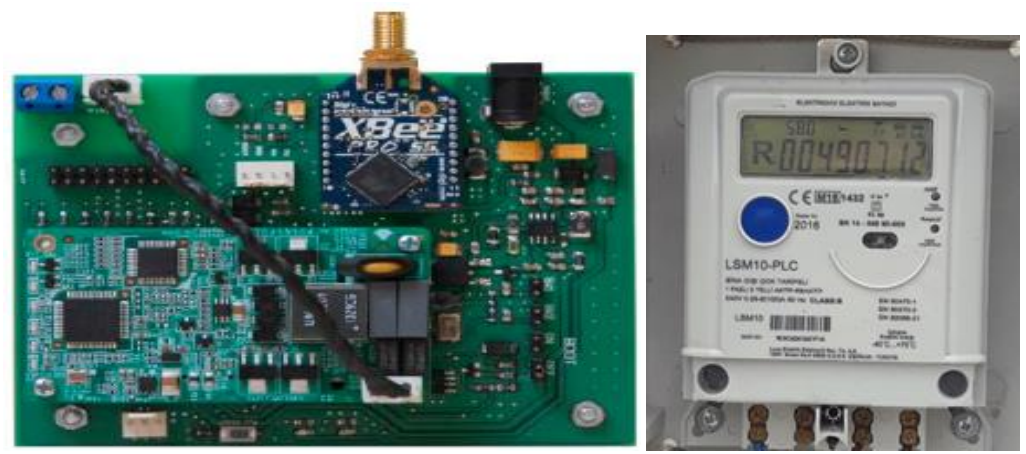

Şekil 4. Kablosuz PLC modüllü ve PLC sayaç

PLC ve kablosuz tabanlı çözüm, farklı yapıdaki ağlar için de kullanılabilir. Şekil 5 'te farklı yapıdaki ağlar için iletişim şematik olarak verilmiştir.

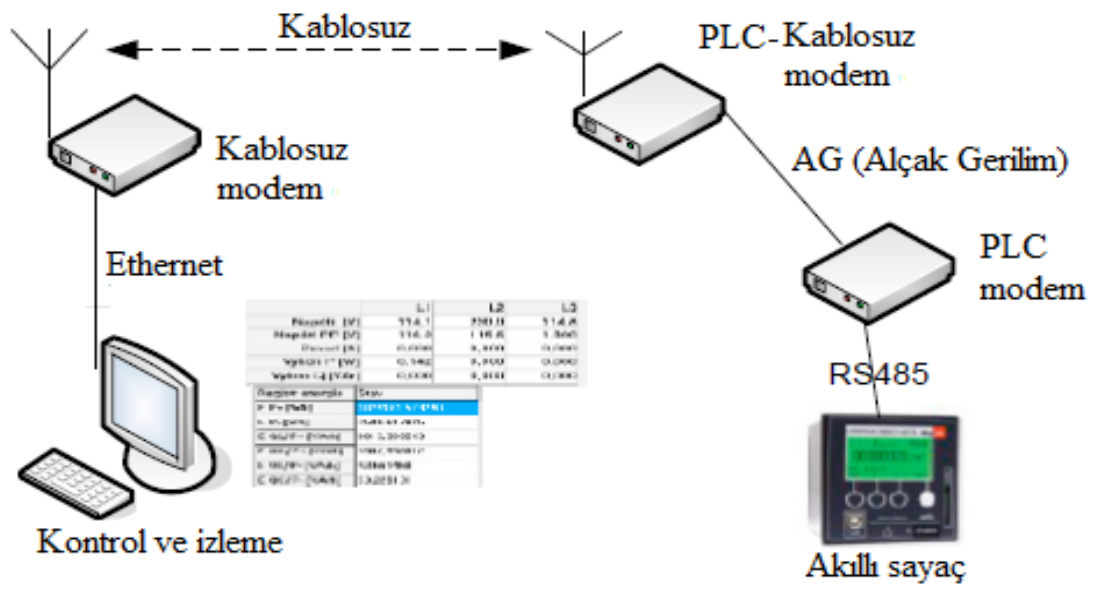

Şekil 5. Farklı yapıdaki ağ [8]

Müstakil evler için modem, trafo binası içerisine, sayaçlar ise dağıtım direkleri üzerine yerleştirilir. Meskenlerin bulunduğu duruma göre bazı direklerde Şekil 6'da görüldüğü gibi tek sayaç, bazı direklerde Şekil 7'de görüldüğü gibi iki sayaç ve bazı direklerde ise Şekil 8'de görüldügü gibi 4 veya daha fazla sayaç bulunabilir. Böyle bir konfigürasyon ile yatırım, işletme ve montaj maliyetleri önemli ölçüde düşürülebilir.

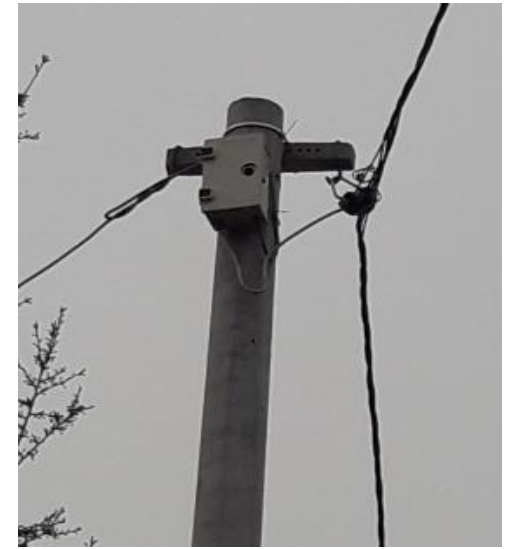

Şekil 6. Tek sayaç

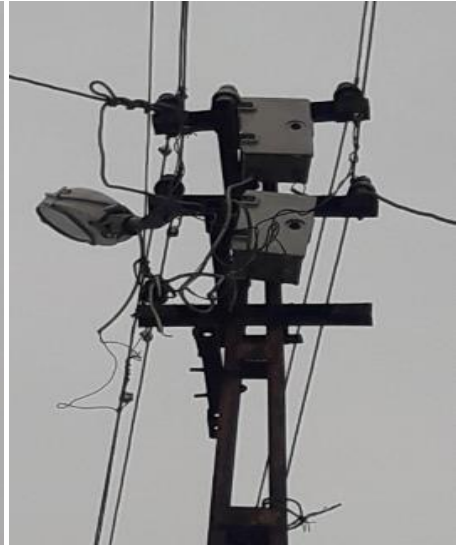

Şekil 7. İki sayaç

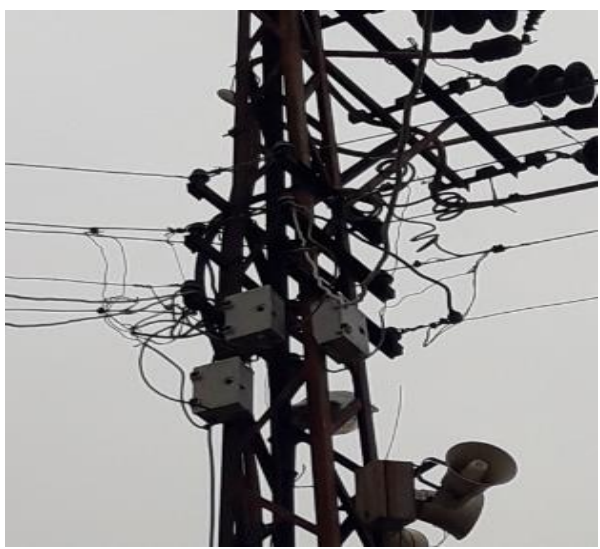

Şekil 8. Dört sayaç

Bu sistem sayesinde bir tüketici(abone), tüketmiş olduğu enerji bedelini süresinde ödemediği taktirde otomatik olarak enerjisi kesilir ve abone ödemesini yaptıktan sonra bir dakika içinde tekrar enerjisini verme imkanı bulunmaktadır. 


\section{Bulgular ve Tartışma}

VEDAŞ tarafından Bulanık, Güroymak, Saray ve Özalp ilçelerinin belli bir kısmında PLC sayaç değişimleri 2016 yılında yapılmıştır. Bir yerleşim yeri içindeki tüketilen elektrik enerjisi miktarı, yılın aynı dönemlerine göre yaklaşık olarak aynı kalmaktadır. Bu nedenle PLC sayaç takılmadan önceki ve takıldıktan sonraki karşılaştırmanın sağlıklı olması için her ilçenin PLC sayaç takılmadan önceki 2016 yılının Ocak, Şubat ve Mart ayları ile PLC sayaç takıldıktan sonraki 2017 yılının Ocak, Şubat ve Mart aylarındaki teknik olmayan kayıplar (kayıp kaçak) dikkate alınarak karşılaştırma yapılmıştır. Tablo 2'de Bulanık ilçesinin kayıp kaçak oranları verilmiştir.

Tablo 2. Bulanık ilçesinin kayıp kaçak oranları

\begin{tabular}{|c|c|c|c|c|c|}
\hline \multicolumn{2}{|c|}{ BULANIK } & 2016 & 2017 & $\begin{array}{c}\text { Değişim } \\
(\mathrm{kWh})\end{array}$ & Değişim (\%) \\
\hline \multirow{4}{*}{ Ocak } & Alınan Enerji & 15.983 .793 & 11.410 .035 & -4.573 .758 & $-28,61$ \\
\cline { 2 - 6 } & Tahakkuk & 3.642 .655 & 5.125 .400 & 1.482 .745 & 40,71 \\
\cline { 2 - 6 } & Kayıp Kaçak & $77,21 \%$ & $55,08 \%$ & $-22,13 \%$ & \\
\hline \multirow{5}{*}{ Şubat } & Alınan Enerji & 14.721 .498 & 11.445 .100 & -3.276 .398 & $-22,26$ \\
\cline { 2 - 6 } & Tahakkuk & 4.372 .403 & 7.049 .470 & 2.677 .067 & 61,23 \\
\cline { 2 - 6 } & Kayıp Kaçak & $70,30 \%$ & $38,41 \%$ & $-31,89 \%$ & \\
\hline \multirow{4}{*}{ Mart } & Alınan Enerji & 13.968 .146 & 7.752 .980 & -6.215 .166 & $-44,50$ \\
\cline { 2 - 6 } & Tahakkuk & 6.723 .153 & 6.069 .498 & -653.655 & $-9,72$ \\
\cline { 2 - 6 } & Kayıp Kaçak & $51,87 \%$ & $21,71 \%$ & $-30,15 \%$ & \\
\hline \multirow{5}{*}{ Toplam 3 Aylık } & Alınan Enerji & 44.673 .437 & 30.608 .115 & -14.065 .322 & $-31,48$ \\
\cline { 2 - 6 } & Tahakkuk & 14.738 .211 & 18.244 .368 & 3.506 .157 & 23,79 \\
\cline { 2 - 6 } & Kayıp Kaçak & $67,01 \%$ & $40,39 \%$ & $-26,62 \%$ & \\
\hline
\end{tabular}

Tablo 2'de görüldüğg̈ gibi Bulanık ilçesinde, 2017 yılının Ocak, Şubat ve Mart aylarında alınan enerji, bir önceki yılın aynı aylarına göre \% 31,48 oranıyla 14.065.322 kWh azalmıştır. Aynı dönemde tahakkuk edilen enerji, \% 23,79 artışla 3.506.157 kWh artmıştır. Benzer şekilde kayıp kaçak oranı \% 26,62 oranında azalmıştır. Tablo 3’te Güroymak ilçesinin kayıp kaçak oranları verilmiştir.

Tablo 3. Güroymak ilçesinin kayıp kaçak oranları

\begin{tabular}{|c|c|c|c|c|c|}
\hline \multicolumn{2}{|c|}{ GÜROYMAK } & 2016 & 2017 & $\begin{array}{c}\text { Değişim } \\
(\mathrm{kWh})\end{array}$ & Değişim (\%) \\
\hline \multirow{4}{*}{ Ocak } & Alınan Enerji & 11.210 .402 & 7.150 .100 & -4.060 .302 & $-36,22$ \\
\cline { 2 - 6 } & Tahakkuk & 2.175 .603 & 3.670 .520 & 1.494 .917 & 68,71 \\
\cline { 2 - 6 } & Kayıp Kaçak & $80,59 \%$ & $48,66 \%$ & $-31,93 \%$ & \\
\hline \multirow{5}{*}{ Şubat } & Alinan Enerji & 10.397 .469 & 6.638 .655 & -3.758 .814 & $-36,15$ \\
\cline { 2 - 6 } & Tahakkuk & 3.629 .814 & 4.663 .350 & 1.033 .536 & 28,47 \\
\cline { 2 - 6 } & Kayıp Kaçak & $65,09 \%$ & $29,75 \%$ & $-35,33 \%$ & \\
\hline \multirow{5}{*}{ Mart } & Alinan Enerji & 10.007 .347 & 5.852 .147 & -4.155 .200 & $-41,52$ \\
\cline { 2 - 6 } & Tahakkuk & 2.440 .286 & 3.651 .003 & 1.210 .717 & 49,61 \\
\cline { 2 - 6 } & Kayıp Kaçak & $75,62 \%$ & $37,61 \%$ & $-38,00 \%$ & \\
\hline \multirow{5}{*}{ Toplam 3 Aylik } & Alinan Enerji & 31.615 .218 & 19.640 .902 & -11.974 .316 & $-37,88$ \\
\cline { 2 - 6 } & Tahakkuk & 8.245 .703 & 11.984 .873 & 3.739 .170 & 45,35 \\
\cline { 2 - 6 } & Kayıp Kaçak & $73,92 \%$ & $38,98 \%$ & $-34,94 \%$ & \\
\hline
\end{tabular}


Tablo 3'te görüldüğü gibi Güroymak ilçesinde, 2017 yılının Ocak, Şubat ve Mart aylarında alınan enerji, bir önceki yılın aynı aylarına göre \% 37,88 oranıyla 11.974.316 kWh azalmıştır. Aynı dönemde tahakkuk edilen enerji, \% 45,35 artışla 3.739.170 kWh artmıştır. Benzer şekilde kayıp kaçak oranı \% 34,94 oranında azalmıştır. Tablo 4'te Özalp ilçesinin kayıp kaçak oranları verilmiştir.

Tablo 4. Özalp ilçesinin kayıp kaçak oranları

\begin{tabular}{|c|c|c|c|c|c|}
\hline \multicolumn{2}{|c|}{ ÖZALP } & 2016 & 2017 & Değişim (kWh) & Değişim (\%) \\
\hline \multirow{3}{*}{ Ocak } & Alınan Enerji & 8.023 .680 & 5.678 .501 & -2.345 .179 & $-29,23$ \\
\hline & Tahakkuk & 2.131 .680 & 4.018 .745 & 1.887 .065 & 88,52 \\
\hline & Kayıp Kaçak & $73,43 \%$ & $29,23 \%$ & $-44,20 \%$ & \\
\hline \multirow{3}{*}{ Şubat } & Alınan Enerji & 7.634 .503 & 4.561 .946 & -3.072 .557 & $-40,25$ \\
\hline & Tahakkuk & 3.480 .425 & 2.722 .909 & -757.516 & $-21,77$ \\
\hline & Kayıp Kaçak & $54,41 \%$ & $40,31 \%$ & $-14,10 \%$ & \\
\hline \multirow{3}{*}{ Mart } & Alınan Enerji & 7.644.363 & 4.430 .270 & -3.214 .093 & $-42,05$ \\
\hline & Tahakkuk & 1.775 .729 & 3.109 .069 & 1.333 .340 & 75,09 \\
\hline & Kayıp Kaçak & $76,77 \%$ & $29,82 \%$ & $-46,95 \%$ & \\
\hline \multirow{3}{*}{ Toplam 3 Aylık } & Alınan Enerji & 23.302 .546 & 14.670 .717 & -8.631 .829 & $-37,04$ \\
\hline & Tahakkuk & 7.387 .834 & 9.850 .723 & 2.462 .889 & 33,34 \\
\hline & Kayıp Kaçak & $68,30 \%$ & $32,85 \%$ & $-35,44 \%$ & \\
\hline
\end{tabular}

Tablo 4'te görüldüğü gibi Özalp ilçesinde, 2017 yılının Ocak, Şubat ve Mart aylarında alınan enerji, bir önceki yılın aynı aylarına göre \% 37,04 oranıyla 8.631.829 kWh azalmıştır. Aynı dönemde tahakkuk edilen enerji, \% 33,34 artışla 2.462.889 kWh artmıştır. Benzer şekilde kayıp kaçak oranı, \% 35,44 oranında azalmıştır. Tablo 5’te Saray ilçesinin kayıp kaçak oranları verilmiştir.

Tablo 5. Saray ilçesinin kayıp kaçak oranları

\begin{tabular}{|c|c|c|c|c|c|}
\hline \multicolumn{2}{|c|}{ SARAY } & 2016 & 2017 & Değişim (kWh) & Değişim (\%) \\
\hline \multirow{4}{*}{ Ocak } & Alınan Enerji & 2.200 .149 & 1.455 .320 & -744.829 & $-33,85$ \\
\cline { 2 - 6 } & Tahakkuk & 479.152 & 1.142 .200 & 663.048 & 138,38 \\
\cline { 2 - 6 } & Kayıp Kaçak & $78,22 \%$ & $21,52 \%$ & $-56,71 \%$ & \\
\hline \multirow{4}{*}{ Şubat } & Alınan Enerji & 2.164 .595 & 1.100 .305 & -1.064 .290 & $-49,17$ \\
\cline { 2 - 6 } & Tahakkuk & 1.159 .785 & 866.821 & -292.964 & $-25,26$ \\
\cline { 2 - 6 } & Kayıp Kaçak & $46,42 \%$ & $21,22 \%$ & $-25,20 \%$ & \\
\hline \multirow{4}{*}{ Mart } & Alınan Enerji & 2.307 .135 & 1.149 .655 & -1.157 .480 & $-50,17$ \\
\cline { 2 - 6 } & Tahakkuk & 1.675 .535 & 1.016 .575 & -658.960 & $-39,33$ \\
\cline { 2 - 6 } & Kayıp Kaçak & $27,38 \%$ & $11,58 \%$ & $-15,80 \%$ & \\
\hline \multirow{4}{*}{ Toplam 3 Aylık } & Alınan Enerji & 6.671 .879 & 3.705 .280 & -2.966 .599 & $-44,46$ \\
\cline { 2 - 6 } & Tahakkuk & 3.314 .472 & 3.025 .596 & -288.876 & $-8,72$ \\
\cline { 2 - 6 } & Kayıp Kaçak & $50,32 \%$ & $18,34 \%$ & $-31,98 \%$ & \\
\hline
\end{tabular}


Tablo 5’te görüldüğü gibi Saray ilçesinde, 2017 yılının Ocak, Şubat ve Mart aylarında alınan enerji, bir önceki yılın aynı aylarına göre \% 44,46 oranıyla $2.966 .599 \mathrm{kWh}$ azalmıştır. Aynı dönemde tahakkuk edilen enerji, \% 8,72 azalmayla $288.876 \mathrm{kWh}$ azalmıştır. Benzer şekilde kayıp kaçak oranı \% 31,98 oranında azalmıştır. Tablo 6'da Bulanık, Güroymak, Saray ve Özalp ilçelerinden oluşan dört ilçenin toplam kayıp kaçak oranları verilmiştir.

Tablo 6. Bulanık, Güroymak, Saray ve Özalp ilçelerinin toplam kayıp kaçak oranları

\begin{tabular}{|c|c|c|c|c|c|}
\hline \multicolumn{2}{|c|}{ TOPLAM (DÖRT İLÇE) } & 2016 & 2017 & Değişim (kWh) & Değişim (\%) \\
\hline \multirow{4}{*}{ Ocak } & Alınan Enerji & 37.418 .024 & 25.693 .956 & -11.724 .068 & $-31,33$ \\
\cline { 2 - 6 } & Tahakkuk & 8.429 .090 & 13.956 .865 & 5.527 .775 & 65,58 \\
\cline { 2 - 6 } & Kayıp Kaçak & $77,47 \%$ & $45,68 \%$ & $-31,79 \%$ & \\
\hline \multirow{4}{*}{ Şubat } & Alınan Enerji & 34.918 .065 & 23.746 .006 & -11.172 .059 & $-32,00$ \\
\cline { 2 - 6 } & Tahakkuk & 12.642 .427 & 15.302 .550 & 2.660 .123 & 21,04 \\
\cline { 2 - 6 } & Kayıp Kaçak & $63,79 \%$ & $35,56 \%$ & $-28,24 \%$ & \\
\hline \multirow{4}{*}{ Mart } & Alınan Enerji & 33.926 .991 & 19.185 .052 & -14.741 .939 & $-43,45$ \\
\cline { 2 - 6 } & Tahakkuk & 12.614 .703 & 13.846 .145 & 1.231 .442 & 9,76 \\
\cline { 2 - 6 } & Kayıp Kaçak & $62,82 \%$ & $27,83 \%$ & $-34,99 \%$ & \\
\hline \multirow{3}{*}{ Toplam 3 Aylık } & Alınan Enerji & 106.263 .080 & 68.625 .014 & -37.638 .066 & $-35,42$ \\
\cline { 2 - 6 } & Tahakkuk & 33.686 .220 & 43.105 .560 & 9.419 .340 & 27,96 \\
\cline { 2 - 6 } & Kayıp Kaçak & $68,30 \%$ & $37,19 \%$ & $-31,11 \%$ & \\
\hline
\end{tabular}

Tablo 6'da görüldüğü gibi Bulanık, Güroymak, Saray ve Özalp ilçelerinden oluşan 4 ilçede, 2017 yılının Ocak, Şubat ve Mart aylarında alınan enerji, bir önceki yılın aynı aylarına göre \% 35,42 oranıyla 37.638.066 kWh azalmıştır. Aynı dönemde tahakkuk edilen enerji, \% 27,96 artışla 9.419.340 kWh artmıştır. Benzer şekilde kayıp kaçak oranı \% 31,11 oranında azalmıştır.

Genel olarak bakıldığında PLC sayaç takıldıktan sonra alınan enerjinin ve kayıp kaçakların azaldığı, tahakkuk edilen enerjinin ise Saray ilçesi dışında arttığı görülmüştür.

\section{Sonuç ve Öneriler}

Elektrik enerjisinin bilinçsiz kullanılması neticesinde üretildiği santralden başlayarak tüketiciye ulaşıncaya kadar olan süreçlerde bir takım kayıplar oluşmaktadır. Enerji ihtiyacımızın her geçen gün artması nedeniyle mevcut enerji sistemlerini daha verimli kullanarak oluşan kayıpları azaltmak önemlidir. Günümüzde akıllı şebeke çözümlerinde kullanılan PLC haberleşme teknolojisi ülkemizde de önemli bir yere sahiptir. Özellikle elektrik dağıtım şirketlerinin üzerinde durduğu konuların başında olan PLC teknolojisinde uzaktan izlemenin yanında açma kesme işlemlerini de merkezi yazılımlar aracılığıyla yapabilmektedirler. Bu nedenle tüketicilerin sayaçlara yaptıkları müdahalelerle kaçak enerji kullanması, bilinçsiz enerji tüketimi ve dağıtım şirketlerinin enerjiyi faturalandırma sırasında yaptıkları yanlışların azaltılması amacıyla akıllı sayaç olan PLC sayaçlar kullanılmaktadır. Yapılan çalışmada, VEDAŞ dağıtım şirketinin Bulanık, Güroymak, Saray ve Özalp ilçelerinin belli bir kısmında uygulamış oldukları PLC sayaç çalışmalarıyla sadece üç aylık dönem için alınan enerji \% 35,42 oranında azalmış, tahakkuk edilen enerji \% 27,96 oranında artmış ve kayıp kaçak oranı da \% 31,11 oranında azalmıştır. Bu uygulamanın tüm tüketici abonelerine uygulanması durumunda kaçak kayıpları daha da azalacak ve enerjinin daha etkin bir şekilde kullanılmasına yardımcı olacaktır. Buradan enerji tüketimindeki kayıp kaçakların azaltılmasında PLC sayaçlarının ne derece önemli olduğunu ortaya çıkartmaktadır. Böylece ülkemizde akıllı sayaçların yaygınlaştırılması için gerekli yarar ve maliyet analizlerinin yapılmasıyla planlanarak hayata geçirilmesi önem kazanmaktadır. Akıllı sayaçlarla birlikte, tüketicilerin tüketmiş oldukları elektrik enerji miktarları uzaktan takip edilip, faturalandırılacaktır. PLC sayaçları kurulan sistemde; iletişim kurmak için daha az maliyet gerektirir 
yani sistemin veri toplama için işletme maliyeti yoktur, sistem verimliliğini artırır. İletişim kurmak ve otomatikleştirmek için müşteri sayısını artırmaya imkan sağlar. Tüketilen elektrik enerjisi gerçek zamanlı olarak izlenebilir. Manuel sayaç okuma maliyetlerinde azalma olur. Geç ve tahmini faturalama maliyetlerinde indirim yapılır. PLC sayaçların geliştirilmiş sayaç doğruluğu ve daha az sayaç bakım masraflarına sahip olmaları gelir kaybında azalmaya sebep olur. Güç kalitesi, kesinti yönetimi ve güvenilirlik sağlanır. Ancak her dağıtım şirketi kendi olanakları doğrultusunda bu çalışmaları yürütmektedir. Bununla birlikte PLC sayaçların elektrik enerjisi kayıp ve kaçakların azaltılmasındaki önemi dikkate alınarak uzaktan sayaç okuma sistemi stratejisi belirlenmeli ve planlı bir şekilde yaygınlaştırmanın başlatılması için gerekli çalışmalar hızlandırılmalıdır. Sadece bir şirket için değil toplam fayda düşünülerek, piyasadaki tüm ortakların aynı ölçüde kendilerine düşen sorumlulukların yerine getirmesini sağlayacak ortamlar oluşturulmalıdır.

\section{Teşekkür}

Bu çalışmada elektrik enerjisi kayıp kaçak oranları için kullanılan veriler, Vangölü Elektrik Dağıtım Anonim Şirketi'nden alınmıştır.

\section{Kaynaklar}

[1] Sargin Ş. 2006. Üretimden Tüketime Elektrik Enerji Sistemlerinde Meydana Gelen Kayıplar ve Giderilmesine Yönelik Çalışmalar. Marmara Üniversitesi, Fen Bilimleri Enstitüsü, Yüksek Lisans Tezi, 270s, İstanbul.

[2] Mungkung N., Gomurut N., Tanitteerapan T., Arunrungrusmi S., Chaokumnerd W., Yuj1 T. 2009. Analysis of Technical Loss in Distribution Line System. Proceedings of the 8th WSEAS International Conference on Telecommunications and Informatics, pp26-30, December 14-16, Canary Islands, Spain.

[3] Kocaman B., Kutlu R. 2016. Bitlis İlindeki Elektrik Enerjisi Dağıtım Kayıplarının İncelenmesi, BEÜ Fen Bilimleri Dergisi, 5 (2): 229-237.

[4] Nazmudeen M.S.H., Wan A.T., Buhari S.M. 2016. Improved Throughput for Power Line Communication (PLC) for Smart Meters using Fog Computing based Data Aggregation Approach, International Smart Cities Conference (ISC2), pp1-4, 12-15 Sept., Trento, Italy.

[5] Galli S., Scaglione A., Wang Z. 2011. For the Grid and Through the Grid: The Role of Power Line Communications in the Smart Grid. Proceedings of the IEEE, 99 (6): 998-1027.

[6] Ribeiro M., Szczupak J., Iravani R., Gu Y., Dash P., Mamishev A. 2007. Emerging signal processing techniques for power quality applications. J. Adv. Signal Processing (EURASIP), 87425:1-4.

[7] Kasztenny B., Hunt R. Vaziri M. 2007. Protection and control redundancy considerations in medium voltage distribution systems. Proc. Annu. Conf. Protective Relay Engineers, pp418-439, 27-29 March, USA.

[8] Mlynek P., Misurec J., Kolka Z., Slacik J., Fujdiak R. 2015. Narrowband Power Line Communication for Smart Metering and Street Lighting Control, IFAC (International Federation of Automatic Control )-PapersOnLine 48-4 : 215-219.

[9] Rinaldi S., Ferrari P., Flammini A., Rizzi M., Sisinni E., Vezzoli A. 2015. Performance analysis of power line communication in industrial power distribution network, Computer Standards \& Interfaces 42: 9-16.

[10] Giustina D.D., Ferrari P., Flammini A., Rinaldi S., Sisinni E. 2013. Automation of distribution gridswith IEC 61850: a first approach using broadband power line communication, IEEE Trans. Instrum. Meas, 62 (9): 2372-2383.

[11] Mrozinski D.1991. New approaches to automatic consumption meter reading in Germany, Comput. Stand. Interfaces, 12 (1): 43-52.

[12] Flammini A., Rinaldi S., Vezzoli A. 2011. The sense of time in open metering system, Proc.of 2011 IEEE International Conference on Smart Measurements for Future Grids (SMFG), Bologna, Italy Nov., pp. 22-27. 
[13] Alonso J.M., Ribas J., Coz J.J.D., Calleja A.J., Corominas E.L., Rico-Secades M. 2000. Development of a distributive control scheme for fluorescent lighting based on LonWorks technology, IEEE Trans. Ind. Electron. 47 (6): 1253-1262.

[14] Yigit M., Gungor V.C., Tuna G., Rangoussi M., Fadel E. 2014. Power line communication technologies for smart grid applications: A review of advances and challenges, Computer Networks, 70: 366-383.

[15] Takmaz E. 2014. Modüler Akı1lı Elektrik Sayacı, 2. Uluslararası İstanbul Akıllı Şebekeler Kongre Fuar1 (ICSG 2014), pp 1-5, 8-9 May1s, İstanbul. 